\title{
Analysis of Mobile Phone Reliability Based on Active Disassembly Using Smart Materials
}

\author{
Zhifeng Liu, Liuxian Zhao, Jun Zhong, Xinyu Li, Huanbo Cheng
}

School of Mechanical and Auto Engineering, Hefei University of Technology, Hefei, China.

Email: zlxlove2008@sina.com

Received March 14 ${ }^{\text {th }}, 2011$; revised April 30 ${ }^{\text {th }}, 2011$; accepted May $8^{\text {th }}, 2011$.

\begin{abstract}
When using shape memory materials into active disassembly of actual electronic products, because the elastic modulus of shape memory materials is affected by the temperature is relatively large, therefore, the main difference of environmental reliability between active disassembly products and common products is the impact of collision and vibration under different temperature. Establishing three-dimensional analysis model, comparing the impact of collision and vibration of mobile phone shells which are made up of PVC materials after casting \& radiation and PC/ABS materials under different temperature. Analyzing the reliability of mobile phone under different temperature and optimizing its structure according to data of testing.
\end{abstract}

Keywords: Active Disassembly, Mobile Phone, Environmental Reliability, Analysis of Collision, Analysis of Vibration

\section{Introduction}

With the rapid development of electronic technology, it is growing demand for electronic products and the pace of elimination of these products is accelerating which result in the serious pollution of environment. Therefore, Design for Disassembly (DfD) of products is getting more and more attention in order to meet the requirements of environment protection [1,2]. However, the current disassembly process of products is only one to one; that is to say, worker can only disassemble one product at one time. It is very difficult to achieve the automation and assembly line of disassembly process of products. What is more, the disassembly process can pose threat to human health. So, it is a growing concern of people about how efficiently to recycle and reuse these obsolete electronic products [3-5].

In recent years, with the deep research and extensive application of smart materials, the method of Active Disassembly using Smart Materials (ADSM) is getting more and more concerns [6-10]. The technology of ADSM was put forward by Dr. Chiodo in Brunel University at 1997 . Active disassembly using smart material (ADSM) is a method using shape memory material to replace fastener, when it is heated to the stimulated temperature, the product can be disassembled actively. The

\footnotetext{
*National Natural Science Foundation of China (50775064).
}

R\&D center of Nokia, Helsinki University of Technology and Helsinki University of Art and Design started to research the active disassembly of mobile phone in cooperation at 2000-2001, which aimed to develop a thermal stimulated mechanical structure for simplifying the recycling process of mobile phone. By testing, the average disassembly time of mobile phone using ADSM is $2 \mathrm{~s}$, which is only $1 / 50$ of the average disassembly time using artificial. Therefore, the method of ADSM can improve the efficiency of disassembly and achieve the economic and efficient recycling of mobile phone. The active disassembly tests of mobile phone and radio are shown in Figure 1 [11].

Any brand of mobile phone needs to go through rigorous testing to verify whether the mobile phone can meet the required reliability norms before sales in the market. Environment is one of the most important factors which affect the reliability of mobile. According to some materials, it is about $52 \%$ accidents of electronic products are caused by environment. Including $40 \%$ are caused by temperature, $27 \%$ are caused by vibration, $19 \%$ are caused by humidity and the remaining accidents are caused by dust, smoke etc [12].

The main difference between active disassembly mobile phone and common mobile phone is that active disassembly mobile phone is made up of smart drives or active disassembly fasteners using shape memory alloy 


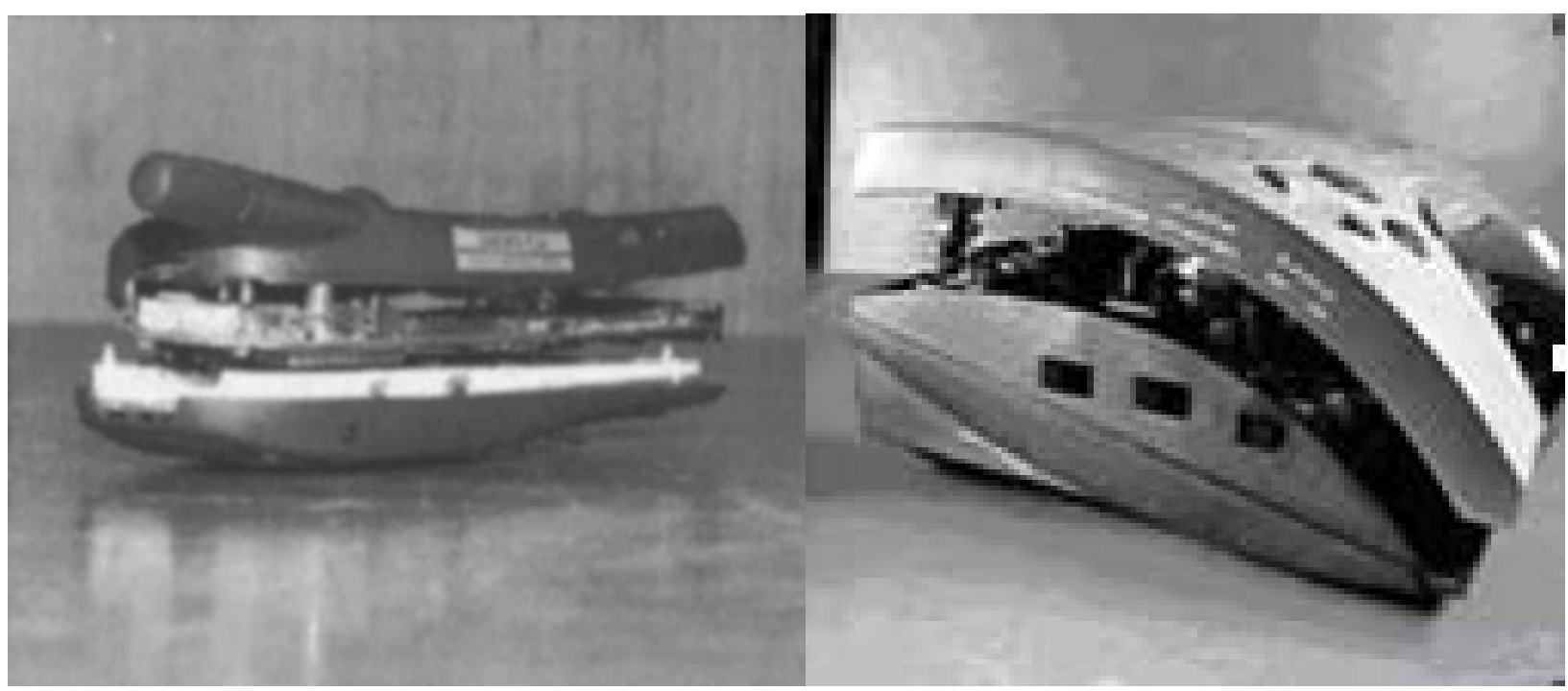

Figure 1. The active disassembly tests of mobile phone and radio [11].

(SMA) or shape memory polymer (SMP). And put the drives and fasteners into the product when design and assembly. Because properties of SMA and SMP are easy to be affected by temperature, so, the main difference of reliability between active disassembly mobile phone and common mobile phone is caused by collision and vibration under different temperature.

\section{Constructing the CAD Model of Active Disassembly Mobile Phone}

Constructing active disassembly mobile phone model used three-dimensional modeling software according to the structure of bar phone. As shown in Figure 2.

In order to be simple and can explain the problem, this phone model consists five parts. Number the parts according to the order from the outside to the inside, 1 front cover, 2 - battery compartment cover, 3 - LCD screen and the circuit board, 4 - battery, 5 - back cover. The active disassembly fasteners of front cover and back cover are made up of PVC material which receives irradiation after casting, the dose of radiation is $4 \mathrm{kGy}$ (SMP for short). There are two L shaped slot in the area of back cover in order to place Ni-Ti memory alloy films which act as drive of disassembling the battery, the drive can be changed by changing the size of memory alloy films, shown in Figure 3.

Here select the stimulation temperature of $\mathrm{Ni}-\mathrm{Ti}$ memory alloy films as $75^{\circ} \mathrm{C}$. The size of phone model is $105 \mathrm{~mm} \times 45 \mathrm{~mm} \times 8 \mathrm{~mm}$, the screen is 2 inch on standard, and the thickness of shell is $1 \mathrm{~mm}$. The shell of common mobile phone is made up of PC/ABS. The properties of the shell of active disassembly mobile phone and common phone are shown in Table 1.
Table 1. The properties of SMP and PC/ABS.

\begin{tabular}{ccccc}
\hline Name & $\begin{array}{c}\text { Density } \\
\mathrm{kg} / \mathrm{m}^{3}\end{array}$ & $\begin{array}{c}\text { Elastic } \\
\text { modulus GPa }\end{array}$ & $\begin{array}{c}\text { Tensile } \\
\text { strength MPa }\end{array}$ & $\begin{array}{c}\text { Poisson's } \\
\text { ratio }\end{array}$ \\
\hline SMP & 1000 & 3.7 & 70 & 0.4 \\
PC/ABS & 1140 & 2.5 & 80 & 0.3 \\
\hline
\end{tabular}

\section{Analysis of Collision of Active Disassembly Mobile Phone}

Simulating the free falling body of mobile phone using computer simulation in order to observe the response of mobile during the process of free falling body.

\subsection{Establishing the Equation of Collision}

Establishing the equation of collision before analyzing the collision of mobile phone using Abaqus. The equation of collision can be described as below under the overall coordinate system.

$$
M a+C v+K d=F^{e x},
$$

in which $M$ means the mass matrix of the structure, $C$ means the damping matrix of the structure, $K$ means the stiffness matrix of the structure, $a$ means the vector of the acceleration, $v$ means the vector of the velocity, $d$ means the vector of the displacement, $F^{e x}$ means he vector of the external forces including the force of collision.

If order $F^{i n}=C v+K d$ and suppose $F^{r e}=F^{e x}-F^{i n}$, then equation of collision can be described as below.

$$
M a=F^{r e},
$$

If use concentrated mass, the mass matrix becomes the diagonal matrix, and then each equation of degree of 
freedom is independent. That is,

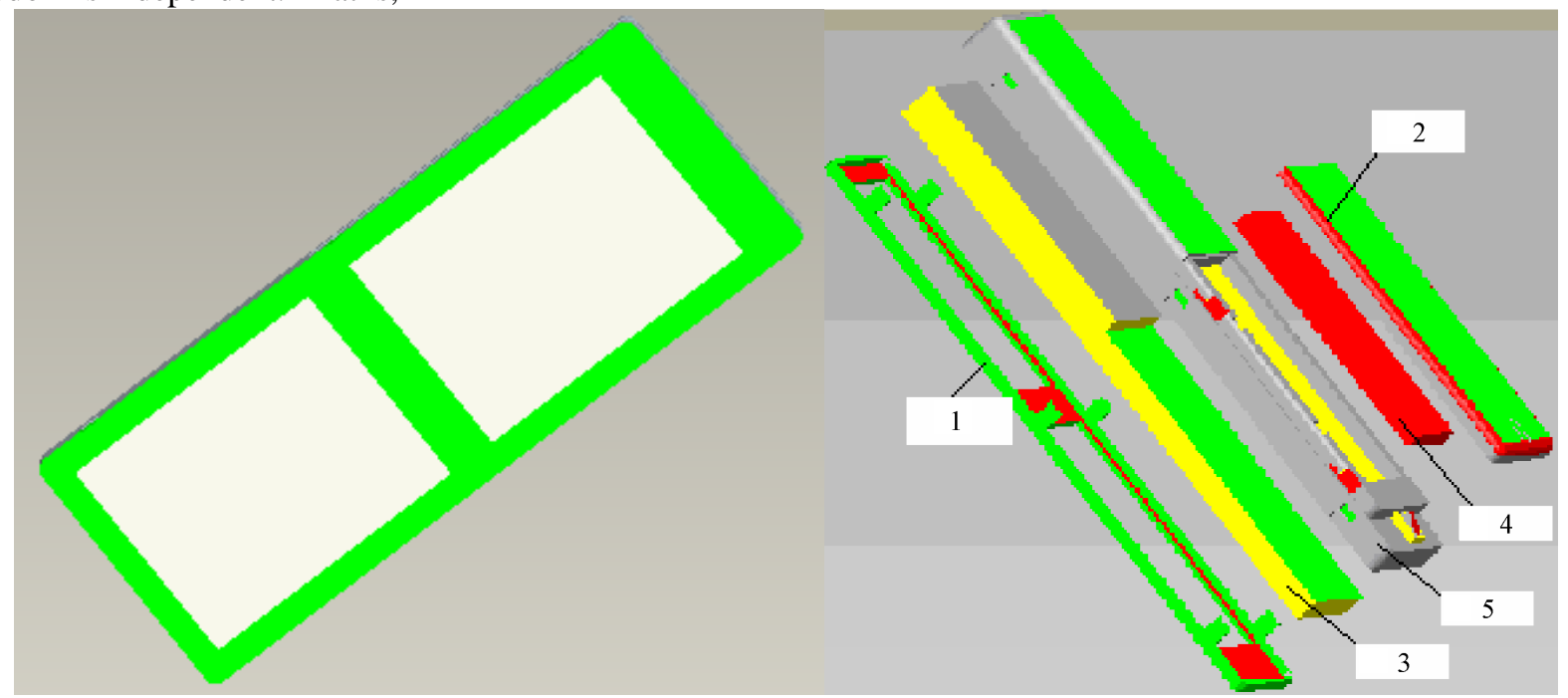

Figure 2. The structure of mobile phone.
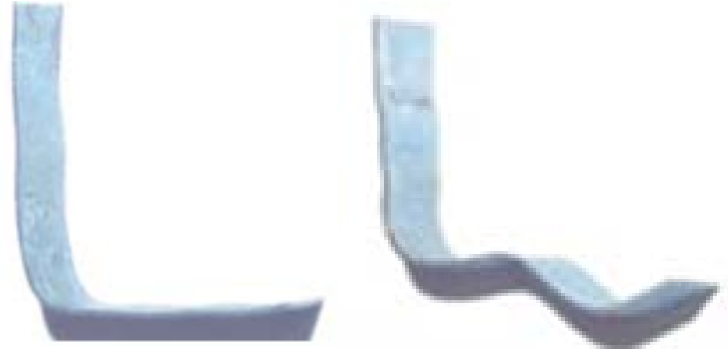

Figure 3. The Ni-Ti memory alloy films before and after deformation.

$$
M_{i} a_{i}=F_{i}^{r e},(i=1,2, \cdots),
$$

Solving the equation of collision using display method, firstly obtain the following equation by Equation (3).

$$
a_{i}=F_{i}^{r e} / M_{i},
$$

Then obtaining the velocity $\left(v_{i}\right)$ by integration of time, obtaining the displacement $\left(d_{i}\right)$ by integration of time once again. Here, the integration of time using display format of central difference. The display format of central difference is described as below.

$$
\left\{\begin{array}{l}
v_{n+1 / 2}=v_{n-1 / 2}+a_{n}\left(\Delta t_{n+1 / 2}+\Delta t_{n-1 / 2}\right) / 2 \\
d_{n+1}=d_{n}+v_{n+1 / 2} \cdot \Delta t_{n+1 / 2} \\
\Delta t_{n+1 / 2}=\left(\Delta t_{n}+\Delta t_{n+1 / 2}\right) / 2
\end{array}\right.
$$

Therefore, obtaining the displacement, velocity and acceleration of each discrete point of time in the overall domain of the time used the above recurrence formula.
The display format of integration does not require solution and reverse solution of matrix, it is not necessary to solve the simultaneous equations and there is no problem of convergence. Therefore, the speed of computation is much fast; the criteria of stability can automatically control the step of time and ensure the speed of integration [13].

\subsection{The Model of Finite Element Analysis}

The experimental condition of the example is shown in Figure 3 . The shell of mobile phone collides with the rigid plane from a height of $2 \mathrm{~mm}$ by free falling body. The element type of mobile phone shell is C3D8R, eight-node, reduced integration, linear, solid element, and the rigid plane uses discrete rigid body for simulation. Selecting the type of parts as discrete rigid body when constructing the model, therefore, it is not necessary to define the properties of materials. Selecting Explicit solver in Abaqus [14]. The properties of materials of mobile phone shell are shown in Table 1.

\subsection{Analysis of the Result of Collision Simulation}

Simulating the mobile phone collides with the rigid plane by Abaqus finite element method. As shown in Figure 4.

It can been seen from Figure 4 that when the temperature is $20^{\circ} \mathrm{C}-60^{\circ} \mathrm{C}$, the maximum stress of mobile phone shell made up of SMP is 67.1 MP when it falls from a height of $2 \mathrm{~m}$, and it does not exceed the tensile strength of SMP which is $70 \mathrm{MP}$. While the maximum stress of mobile phone shell made up of PC/ABS is 119 MP under the same condition, which exceeds the tensile strength of PC/ABS. Therefore, the mobile phone made 
up of PC/ABS can be destroyed falling on the rigid plane from a height of $2 \mathrm{~m}$ at room temperature. Thus, the re-
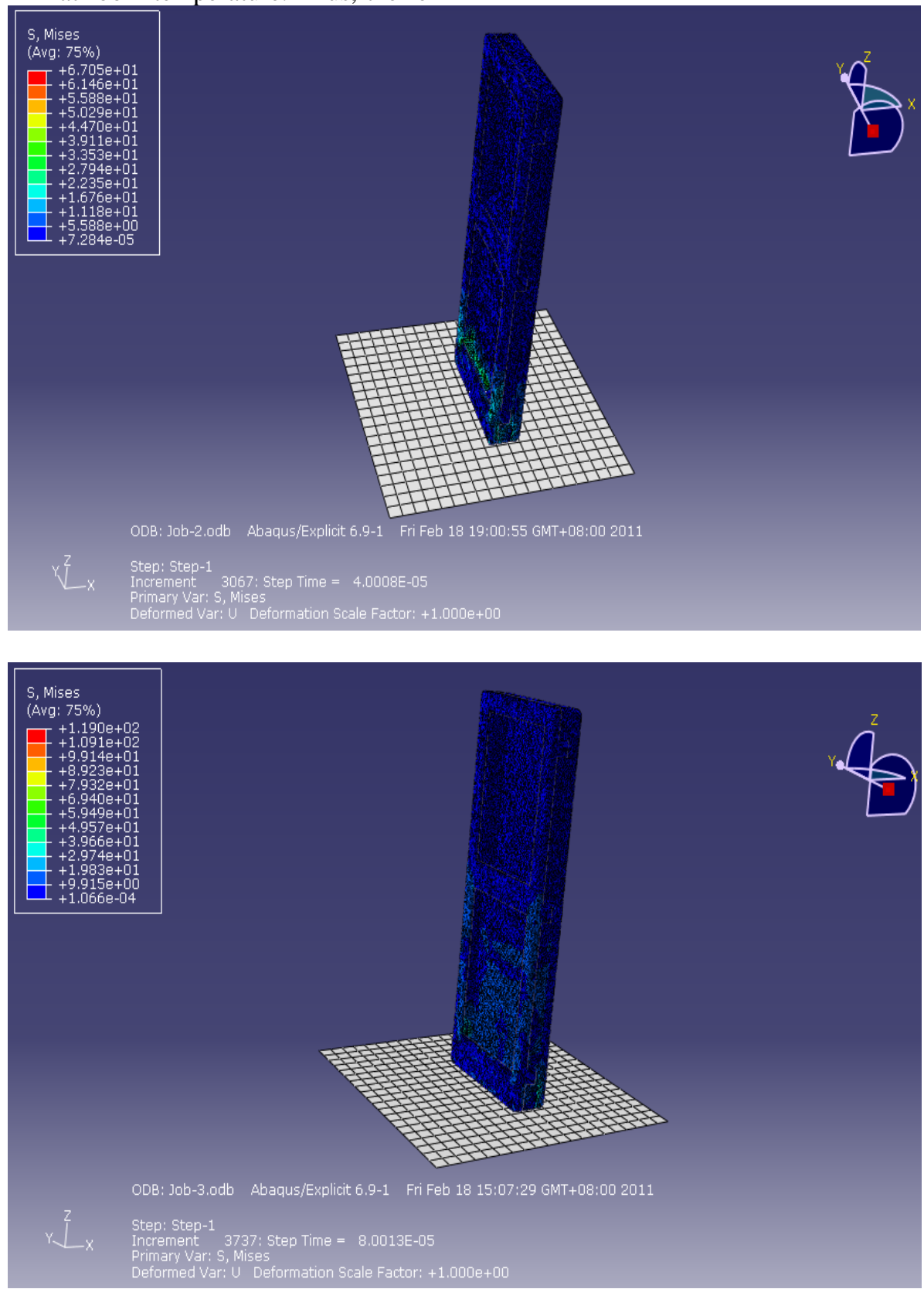

Figure 4. The collision experiment of mobile phone using SMP and PC/ABS.

the reliability of mobile phone made up of PC/ABS.

The maximum stress of collision of active disassembly mobile phone and the common mobile phone under different temperature are shown in Table 2 and Table 3.

\section{Analysis of Vibration of Active Disassembly Mobile Phone}

\subsection{The Analysis Model of Mobile Phone}

The analysis of vibration of mobile phone mainly analyzes whether the vibration can cause the fasteners between front cover and back cover to detach. Therefore, just analyzing the displacement of fasteners between front cover and back cover is enough. The properties of materials of mobile phone shell are shown in Table 1. The parameters of mobile phone motor are shown in Table 4 . The vibration time of motor is $5 \mathrm{~s}$. 


\subsection{Analysis of the Result of Vibration Simulation}

The mobile phone can only move alternatively along the Table 2. The maximum stress of collision of active disassembly mobile phone under different temperature.

\begin{tabular}{ccc}
\hline Temperature ${ }^{\circ} \mathrm{C}$ & $\begin{array}{c}\text { The maximum } \\
\text { temperature MPa }\end{array}$ & $\begin{array}{c}\text { Tensile strength } \\
\mathrm{MPa}\end{array}$ \\
\hline $20-60$ & 67.1 & 70 \\
70 & 36.5 & 12.9 \\
\hline
\end{tabular}

Table 3. The maximum stress of collision of common mobile phone under different temperature.

\begin{tabular}{ccc}
\hline Temperature ${ }^{\circ} \mathrm{C}$ & $\begin{array}{c}\text { The maximum } \\
\text { temperature MPa }\end{array}$ & $\begin{array}{c}\text { Tensile strength } \\
\mathrm{MPa}\end{array}$ \\
\hline $20-40$ & 119 & 80 \\
\hline
\end{tabular}

Table 4. The parameters of motor.

\begin{tabular}{ccccc}
\hline $\begin{array}{c}\text { Rated voltage } \\
\text { V (DC) }\end{array}$ & $\begin{array}{c}\text { Rated } \\
\text { Current (mA) }\end{array}$ & $\begin{array}{c}\text { Rated Speed } \\
\text { R/M }\end{array}$ & $\begin{array}{c}\text { Hammer } \\
\text { length mm }\end{array}$ & Mass g \\
\hline 3.0 & 80 & 20000 & 5 & 2 \\
\hline
\end{tabular}

$\mathrm{Z}$ direction using finite element method of Abaqus. Therefore, it is necessary to define the constraints of $\mathrm{X}$, $\mathrm{Y}$ directions and three rotation directions. The mobile phone suffers a sinusoidal alternating load, the amplitude is $2 \mathrm{~mm}$, the result is shown in Figure 5.

It can be seen from Figure $\mathbf{5}$ that the maximum stress of front cover made up of SMP is $3.96 \mathrm{MP}$ under the temperature of $20^{\circ} \mathrm{C}-60^{\circ} \mathrm{C}$, and the maximum displace-

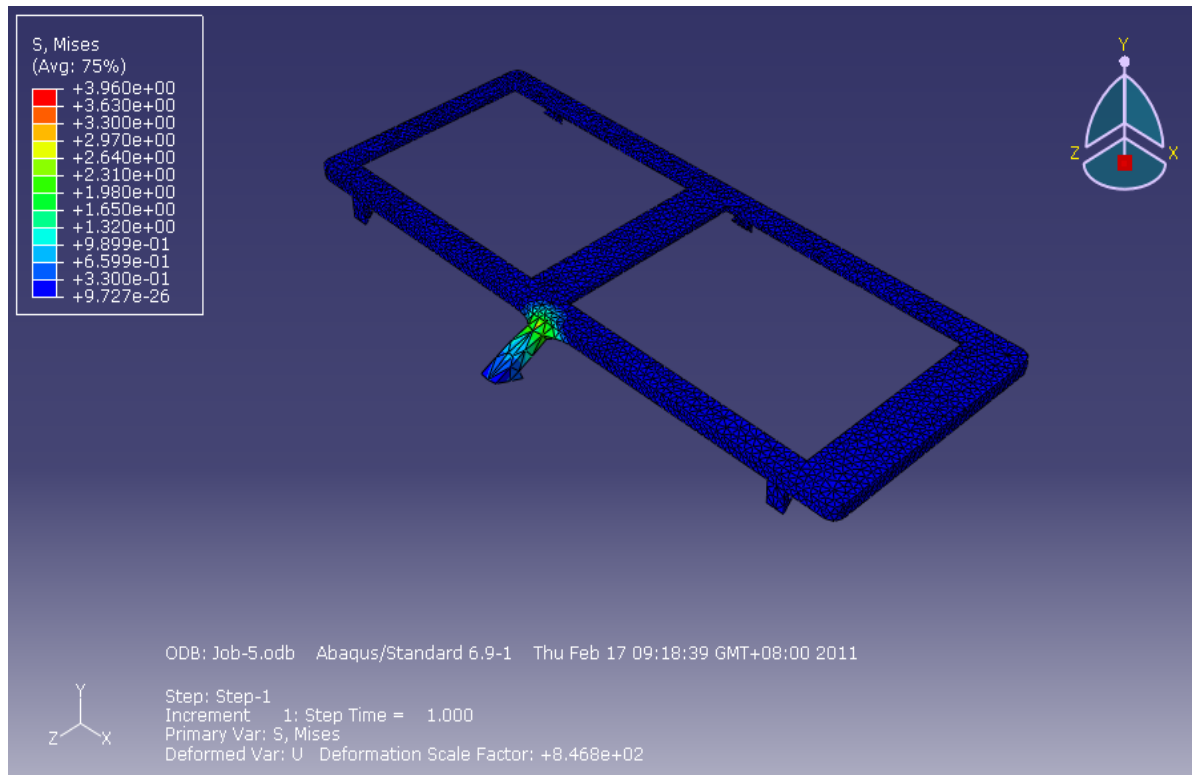




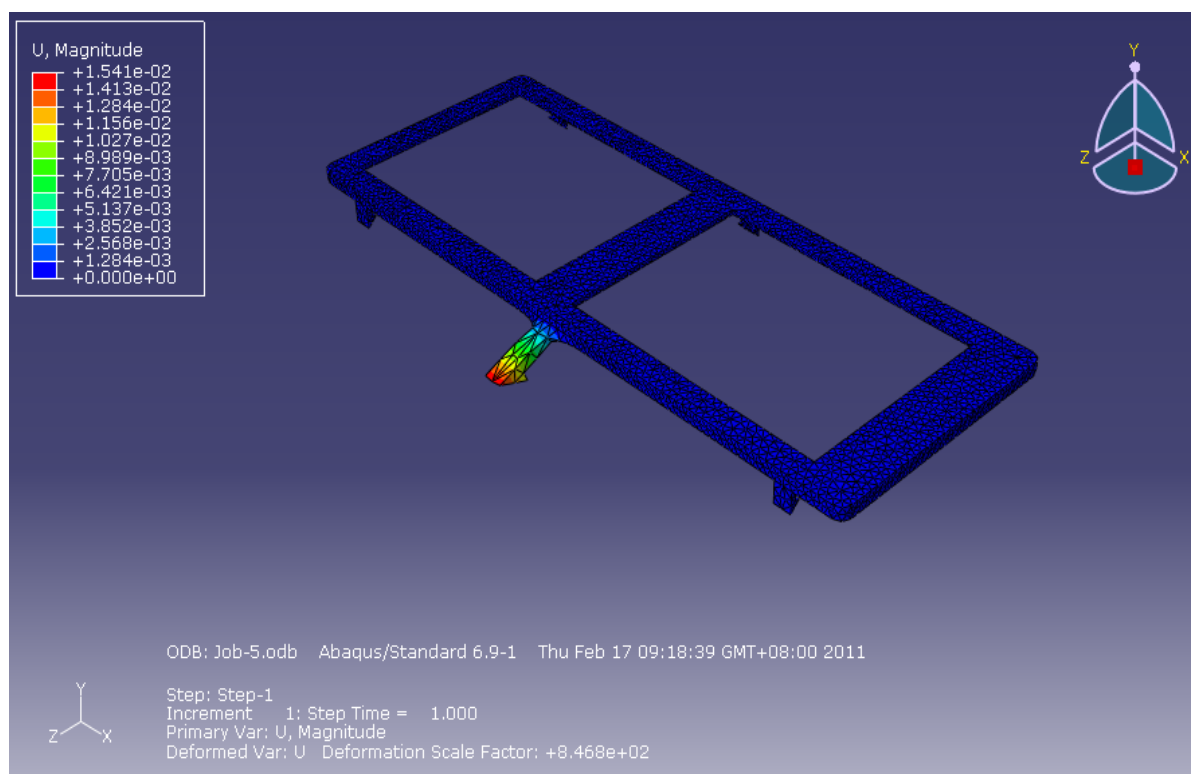

Figure 5. The collision experiment of mobile phone using SMP.

ment is $1.54 \times 10^{-2} \mathrm{~mm}$, while the length of connection between front cover and back cover is $0.8 \mathrm{~mm}$, therefore, the fasteners between front cover and back cover do not detach and it ensures the reliability of vibration of mobile phone. The maximum stress of vibration of active disassembly mobile phone under different temperature is shown in Table 5.

For easy comparison, conducting the same analysis of mobile phone made up of PC/ABS, the result is shown in Figure 6.
It can be seen from Figure 6 that the maximum stress of front cover made up of PC/ABS is $0.12 \mathrm{MP}$, and the maximum displacement is $2.74 \times 10^{--2} \mathrm{~mm}$, while the length of connection between front cover and back cover is $0.8 \mathrm{~mm}$, therefore, the fasteners between front cover and back cover do not detach and it ensures the reliability of vibration of mobile phone. The maximum stress of vibration of mobile phone made up of PC/ABS under different temperature is shown in Table 6.

The vibration reliability of mobile phone made up of

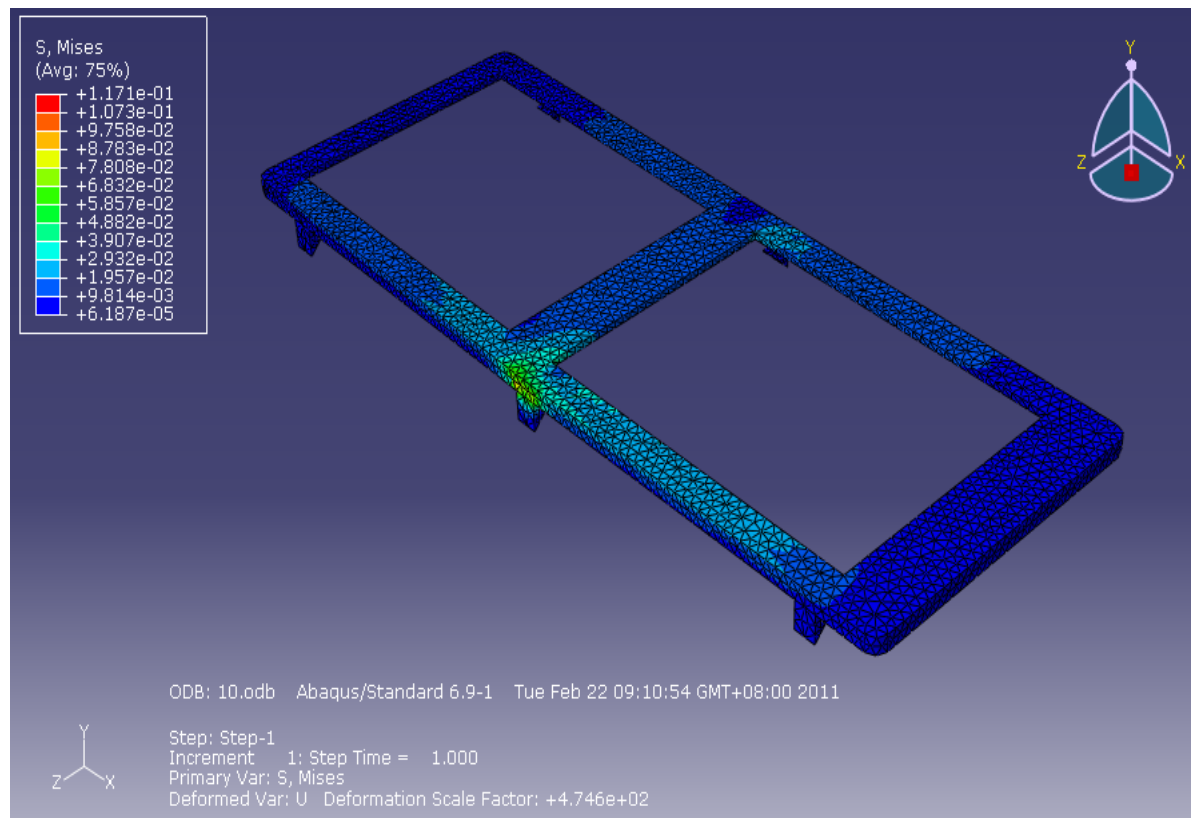




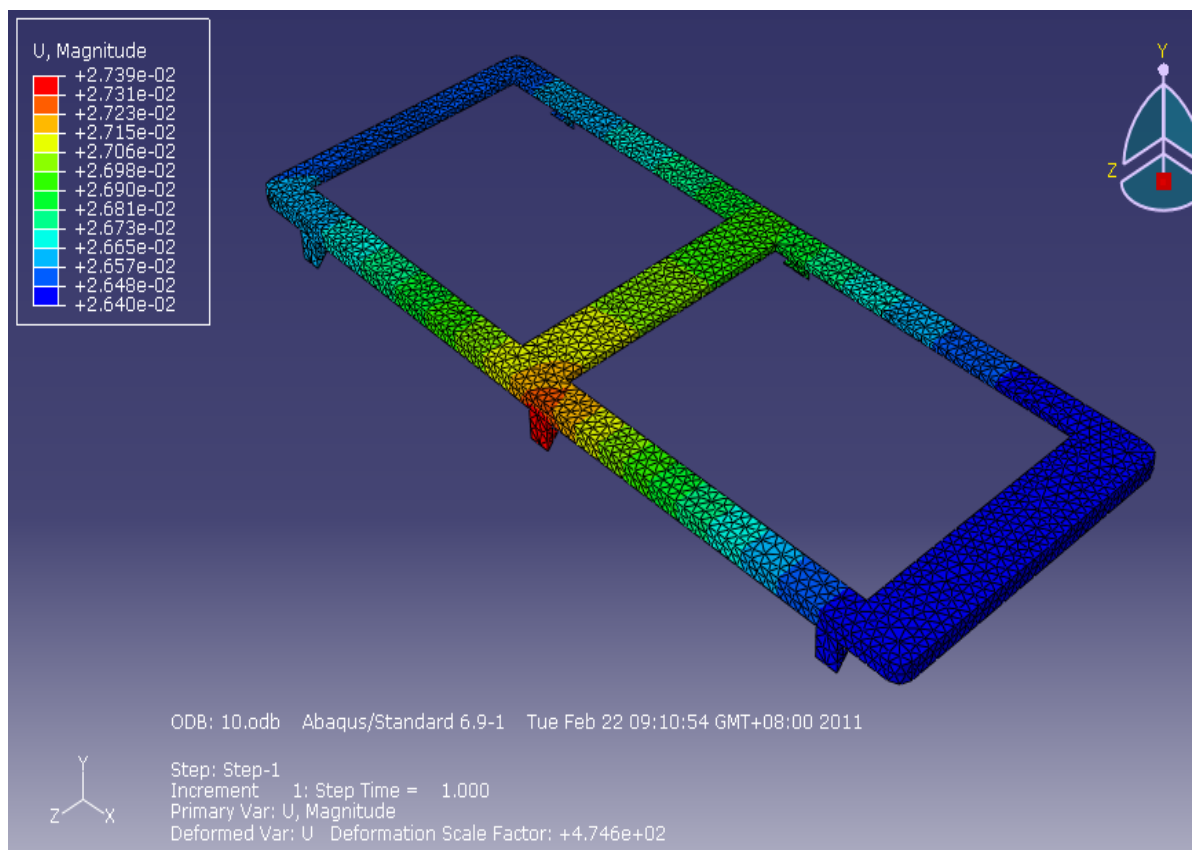

Figure 6. The collision experiment of mobile phone using PC/ABS.

Table 5. The maximum stress of vibration of active disassembly mobile phone under different temperature.

\begin{tabular}{ccc}
\hline Temperature ${ }^{\circ} \mathrm{C}$ & $\begin{array}{c}\text { Maximum } \\
\text { displacement mm }\end{array}$ & $\begin{array}{c}\text { The length of } \\
\text { connection of } \\
\text { fasteners mm }\end{array}$ \\
\hline $20-60$ & $1.54 \times 10^{-2}$ & 0.8 \\
70 & $7.15 \times 10^{-2}$ & 0.8 \\
80 & $3.32 \times 10^{-2}$ & 0.8 \\
90 & 1.54 & 0.8 \\
\hline
\end{tabular}

Table 6. The maximum stress of vibration of mobile phone made up of PC/ABS under different temperature.

\begin{tabular}{ccc}
\hline Temperature ${ }^{\circ} \mathrm{C}$ & $\begin{array}{c}\text { Maximum } \\
\text { displacement mm }\end{array}$ & $\begin{array}{c}\text { The length of } \\
\text { connection of } \\
\text { fasteners mm }\end{array}$ \\
\hline $20-40$ & $2.74 \times 10^{-2}$ & 0.8 \\
90 & $1.18 \times 10^{-2}$ & 0.8 \\
\hline
\end{tabular}

PC/ABS is higher than the vibration reliability of mobile phone made up of SMP by comparison.

\subsection{Optimizing the Structure of Mobile Phone}

In order to expand the stress of collision and vibration quickly to other locations around the shell and obtain better mechanical performance, it is necessary to replace the material of fillet of mobile phone into magnesium alloy material, as shown in Figure 7 [15]. Currently, the price of magnesium alloy shell is about the double of plastic shell. However, the mass of magnesium alloy is light, the density is low, the resistance to stress is relatively strong, the hardness is several times more than traditional plastic, but its weight is only $1 / 3$ of ordinary plastic. Therefore, it can improve the reliability of mobile phone using magnesium alloy shell. What is more, it can make the product more attractive by treating the surface of magnesium alloy. Therefore, magnesium alloy shell can be used in high-end mobile phones [15].

\section{Conclusions}

1) The mobile phone made up of SMP is not destroyed falling from a height of $2 \mathrm{~m}$ under the room temperature, while the mobile phone made up of PC/ABS is destroyed under the same conditions. Therefore, the collision reliability of mobile phone shell made up of PVC material which receives irradiation after casting is higher than the collision reliability of mobile phone shell made up of PC/ABS. And it can improve the collision reliability using magnesium alloy shell of mobile phone.

2) The mobile phone made up of SMP and the mobile phone made up of PC/ABS both can ensure the reliability 


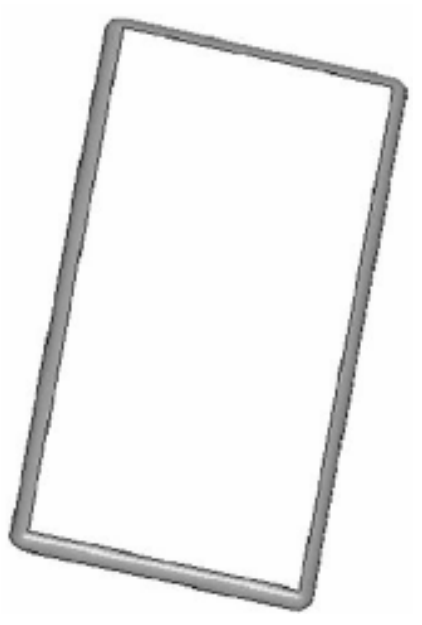

Figure 7. Magnesium alloy shell of mobile phone.

of vibration under room temperature. Because the property of SMP is easily affected by the temperature, the elastic modulus of SMP declines sharply under hightemperature condition which results in the reliability of mobile phone made up of SMP is relatively low. While the elastic modulus of PC/ABS affected by the temperature is not so large, therefore, the mobile phone made up of $\mathrm{PC} / \mathrm{ABS}$ can ensure the reliability of vibration under the temperature of $90^{\circ} \mathrm{C}$.

3) Mobile phone is used under the room temperature because the electronic components of mobile phone are easily destroyed under high temperature. The mobile phone made up of SMP can ensure the reliability of collision and vibration under room temperature, therefore, the mobile phone made up of SMP meets the environmental reliability.

\section{Outlook}

It is necessary to analyze the reliability of multi-step active disassembly products, such as the impact of collision and vibration on multi-step active disassembly mobile phone. What is more, it is necessary to research the impact of active disassembly on the economy and environment of products.

\section{Acknowledgements}

Thanks to the support of NSFC item: 50775064.

\section{REFERENCES}

[1] W. Xu and J. H. Tao, "Research of Recycling Oriented Disassembly Technology,” Machine Tool \& Hydraulics, Vol. 37, No. 2, 2009, pp. 24-28.

[2] K. Lee and R Gadh, "Computer Aided Design for Disassembly: A Destructive Approach," Proceedings of the 1996 IEEE International Symposium on Electronics \& the Environment, New Jersey, 1999, pp. 173-178.
[3] R. C. Li, J. J. Tang, X. Hong and K. G. Wu, "Harmful Influence to Environment and Recycling of Discarded Household Appliance," Environmental Pollution and Control, Vol. 25, No. 4, 2003, pp. 109-110.

[4] F. H. Lian, Q. P. Su, M. H. Wang, Y. Zhang and G. H. Tang, "Recycling and Disposal of the Old and Waste Household Appliances," Environmental Pollution and Control, Vol. 26, No. 1, 2004, pp. 67-69.

[5] J. Z. Li, P. Shrivastava and Z. Gao, "Printed Circuit Board Recycling: A State-of-the-Art Survey,” Proceeding of the 2002 IEEE International Symposium on Electronics and the Environment, Vol. 27, 2004, pp. 234-241.

[6] K. Lee and R. Gadh, "Computer Aided Design for Disassembly: A Destructive Approach" Proceedings of the 1996 IEEE International Symposium on Electronics \& the Environment, New Jersey, 1999, pp. 173-178.

[7] J. D. Chiodo, E. H. Billett and D. J. Harrison, "Preliminary Investigations of Active Disassembly Using Shape Memory Polymers," Proceedings First International Symposium on Environmentally Conscious Design and Inverse Manufacturing, Tokyo, 1999, pp. 590-595.

[8] S. Seelecke, "Shape Memory Alloy Actuators in Smart Structures: Modeling and simulation,” American Society of Mechanical Engineers, Vol. 57, No. 1, 2004, pp. 23-46.

[9] Z. F. Liu, X. Y. Li and H. C. Zhang, "Research on Design Methods of Products Based on ADSM," Chinese Journal of Mechanical Engineering, 2009, Vol. 45, No. 10, pp. 192-197. doi:10.3901/JME.2009.10.192

[10] Z. F. Liu, L. X. Zhao, X. Y. Li, H. C. Zhang and H. B. Cheng, "Research on Multi-Step Active Disassembly Method of products Based on ADSM," Conference of Manufacturing Engineering and Automation, Vol. 139141, Guangzhou, 2010, pp. 1428-1432.

[11] J. D. Chiodo and C. Boks, “Assessment of End-of-Life Strategies with Active Disassembly Using Smart Materials,” The Journal of Sustainable Product Design, Vol. 2, No. 1-2, 2002, pp. 69-82. doi:10.1023/B:JSPD.0000016422.01386.7c

[12] J. Peng, "Humid and Hot Environment and Electronic Product Reliability,” Electronic Product Reliability and Environmental Testing, Vol. 5, 2003, pp. 57-60.

[13] J. P. Zu and C. Q. Xu, "The Simulation and Investigation for Free - Drop of Mobile Phone,” Manufacture Information Engineering of China, Vol. 35, No. 11, 2006, pp. 68-70.

[14] J. Ding, G. Li, C. Q. Xue and L. Yu, “A Study on Anti-impact Property of the Bottom Shape of Plastic Mobile Phone Case,” Electro-Mechanical Engineering, Vol. 25, No. 1, 2009, pp. 42-48.

[15] B. Y. Peng, J. B. Xie, Q. H. Feng and G. F. Yin, "Digitalized Analysis of Open-faced Mobile Phone Damage Caused by Falling," Journal of Xihua University, Vol. 28, No. 1, 2009, pp. 74-77. 
